\title{
Eimeria pavoaegyptica sp. nov. (Apicomplexa: Eimeriidae) in faeces of Indian peacocks, Pavo cristatus Linnaeus, 1758 (Galliformes: Phasianidae) from Egypt
}

\author{
Ismail Saad El-Shahawy \\ Department of Parasitology, Faculty of Veterinary Medicine, South Valley University, Egypt
}

Coprological examination of 15 Indian peacocks, Pavo cristatus, revealed the presence of a coccidium species of the genus Eimeria, which apparently represents a previously undescribed species. Sporulation is exogenous and fully developed oocysts of Eimeria pavoaegyptica sp. nov. are ellipsoidal, with a dimension of 15 (13-16) $\times 12$ (1012.9) $\mu \mathrm{m}$ and with a shape index of 1.25 (1-1.3). The sporulated oocysts have no micropyle but enclose one large rectangular-shaped polar granule and an oocyst residuum. The oocysts have a distinct two-layered wall, which is $\sim 1.7 \mu \mathrm{m}$ thick. The outer layer has a smooth texture; it fills $\sim 3 / 4$ of the total thickness and appears bicolored. The sporocysts are boat-shaped, of about 10 (9-11) $\times 4$ (4-4.7) $\mu \mathrm{m}$; their average shape-index is $2.5 \mu \mathrm{m}$ with a small pointed Stieda body and a smooth, thin single-layered wall. No substieda body is detected. The sporocysts contain numerous, nearly uniform granular residua. The sporozoites are banana-shaped, $6 \times 3 \mu \mathrm{m}$ and each has two different-sized refractile bodies.

Key words: coccidia - apicomplexa - Eimeria - peacock - Pavo cristatus - Egypt

Although parasitic infections are among the most common sanitary problems affecting wild birds and can become either a subclinical condition or even a cause of death (Freitas et al. 2002), they have received attention only when they have threatened agriculture or human health (Daszak et al. 2000).

Indian peacocks, Pavo cristatus Linnaeus, 1758, are uniquely large colorful birds, particularly the males, and are among the most colorful and striking birds of the entire poultry world. Moreover, most people are familiar with them from visits to zoos and parks.

Unfortunately, like other captive birds, they are suffering from potential stress and frequent cases of parasitic infections, which are among the most prevalent diseases that afflict them. Among parasitic diseases, the ones caused by protozoa, especially coccidiosis, are common and cause the most severe health and economic problems worldwide. These infections result in poor growth, diarrhea and high mortality, particularly in young birds. This disease is caused by a species of protozoa in the genus Eimeria Schneider, 1875, which parasitize the intestinal mucosa.

Although South Asia, particularly India, is the area with the highest diversity of Indian peacock species, only five species of Eimeria have been described so far from their faeces in this region (Banik \& Ray 1961, 1964, Mandal 1965, Bhatia \& Pande 1966, Ray 1966). Amoudi (1988) described two new species of Eimeria from the faeces of

Corresponding author: dr.ismail_para@yahoo.com

Received 12 March 2010

Accepted 16 June 2010 local Indian peacocks reared in the experimental agriculture station of King Saud University, Saudi Arabia. Similarly, Alyousif and Al-Shawa (1998) further examined several Eimeria species such as Eimeria mayurai (Bhatia \& Pande 1966), Eimeria pavonina (Banik \& Ray 1961) and Eimeria pavonis (Mandal 1965) (Indian species) and they also gave a description of a new Eimerian species from the faeces of the local green peacocks Pavo muticus of the Al-Kharj area in central Saudi Arabia.

During a survey of parasites in zoo birds, carried out in the zoological park of El-Gharbia governorate, Egypt, I discovered a species of Eimeria in the faeces of Indian peacocks, which is different from all known species and, therefore, is herein described as a new species.

\section{MATERIALS AND METHODS}

Freshly egested faecal samples of 15 identified, captive P. cristatus (Galliformes: Phasianidae) individuals were collected from the ground of their cages at the El-Gharbia city zoo and submitted to the parasitology laboratory of the Faculty of Veterinary Medicine, South Valley University, for a parasitological examination. The samples were preserved in a cold icebox and stored at $4^{\circ} \mathrm{C}$ until the day of the examination. A direct smear method and a flotation technique were used to detect oocysts. The samples that contained abundant unsporulated oocysts were placed in Petri dishes, forming a thin layer of liquid $(\sim 5 \mathrm{~mm})$ of $2.5 \%(\mathrm{w} / \mathrm{v})$ aqueous potassium dichromate solution $\left(\mathrm{K}_{2} \mathrm{Cr}_{2} \mathrm{O}_{7}\right)$ and incubated at room temperature (RT) $\left(23^{\circ} \mathrm{C}\right)$ to promote sporulation. The oocysts were repeatedly examined over a period of one week and the sporulation time was recorded. Forty sporulated oocysts and their inner structures were examined after concentration by flotation using a saturated sodium chloride solution for $5 \mathrm{~min}$ at 1,500 RPM (Brown \& Neva 1983). Morphological observations were performed ac- 
cording to Duszynski and Wilber (1997) and Wilber et al. (1998). These morphological observations included several oocyst characters such as length (L), width $(\mathrm{W})$ and their ranges and ratio $(\mathrm{L} / \mathrm{W})$, micropyle (M), micropylar, oocyst residuum (OR) and polar granule (PG). In addition, the sporocyst characters observed included L, W and their L/W, Stieda body (SB), substieda body (SSB), sporocyst residuum (SR), sporozoites (SP), refractile bodies (RBs) and nucleus (N) in SP. The measurements were performed by using a binocular microscope Lieca equipped with a calibrated ocular micrometer. All measurements in the text are given in micrometers $(\mu \mathrm{m})$ and are means followed by the ranges in parentheses. Photomicrographs and line-drawings were made with a binocular microscope Leica Leitz BioMed and using a digital camera Wild MPS 32 and Wild M3X, respectively. The species identification was based on the complex morphology of the sporulated eimerian oocyst (Pellerdy 1965, Soulsby 1982, Levine 1985).

\section{RESULTS}

Out of the 15 adult caged Indian peacocks examined, four of them $(26.66 \%)$ had coccidian oocysts. A morphological comparison of the coccidian species revealed differences between them and one of them is a new species in the genus Eimeria described below.

\section{Eimeria pavoaegyptica sp. nov.}

(Figs 1, 2)

Description of sporulated oocyst - The oocyst shape is ellipsoidal, the oocyst dimensions are $\mathrm{L} \times \mathrm{W}$ (40) 15 $(13-16) \times 12(10-12.9)$; L/W ratio, 1.25 (1-1.3); number of walls: two; wall thickness 1.7 (1.1-1.8); wall characteristics: outer wall smooth, $\sim 3 / 4$ of total thickness and appears bicolored, the outermost portion is red-brown, the innermost portion yellowish to green. The inner wall is dark brown, $\sim 1 / 4$ of total thickness and separated from outer wall by a dark brown line. The $\mathrm{M}$ is absent. One large, prominent, refractile PG is present. It lies underneath the narrow end of the oocyst and is usually rectangular in shape with a dimension of $\sim 0.3 \times 0.6$. An OR is present with an average diameter of $\sim 2$ and it consists of one to three small homogenous globules scattered throughout the oocyst; one of the globules is near the middle part of the oocyst and the others are found near the bottom of the oocyst and above the sporocyst.

Distinctive features of the oocyst - It is a considerably small oocyst, the $\mathrm{M}$ is absent, with prominent $\mathrm{PG}$, distinct $\mathrm{OR}$ and thick bicolored outer wall, with red-brown outer portion and yellowish to green inner portion.

Description of sporocyst and SP - The genus Eimeria is, among others, characterized by four sporocysts within the oocyst; each of them is boat-shaped, $\mathrm{L} \times \mathrm{W}$ (40) $10(9-11) \times 4(4-4.7)$; L/W ratio, 2.5 (1.9-2.8). The SB is present and is small and pointed, of $\sim 0.8 \mathrm{high}$ and 1.2 wide, but the SSB is not detected. The SR is present and consists of numerous, nearly uniform granules covering the SP. The SP are banana-shaped, broad at one end (posterior) and slightly tapering at the other, $\mathrm{L} \times \mathrm{W}$

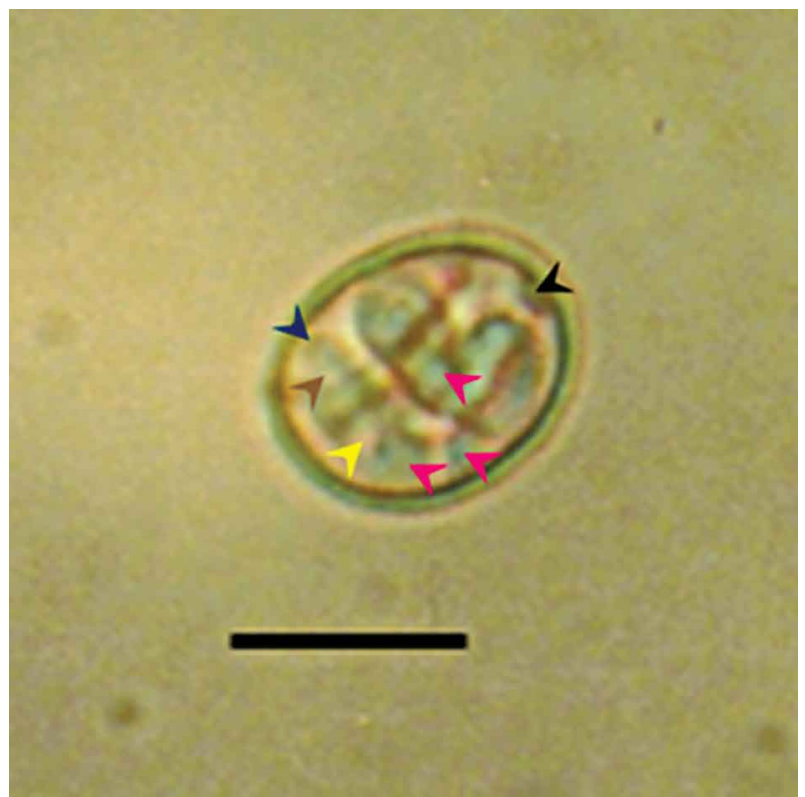

Fig. 1: photomicrographs of living, sporulated oocyst of Eimeria pavoaegyptica sp. nov. recovered from the faeces of peacocks in Egypt. Oocyst showing polar granule (black arrow), residuum (red arrow), large refractile body (yellow arrow), small refractile body (brown arrow) and Stieda body (blue arrow). $\mathrm{Bar}=10 \mu \mathrm{m}$.

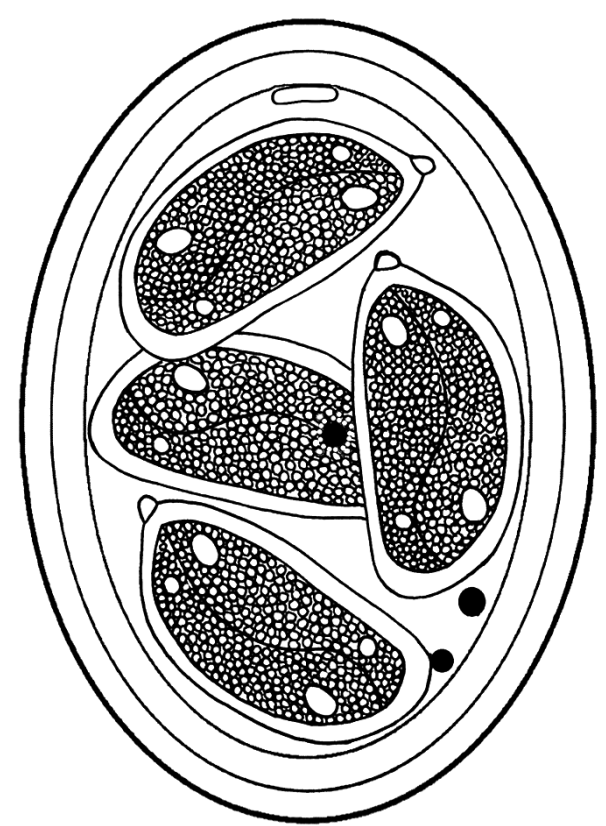

Fig. 2: composite line drawing of a sporulated oocyst of Eimeria pavoaegyptica sp. nov. $\mathrm{Bar}=10 \mu \mathrm{m}$.

$6 \times 3$, lying lengthwise in a head to tail pattern. Each SP has a large, clear subspheroid RB in the posterior end and a smaller, rounded anterior one in the opposite end. The N of SP is not discernible. A thin membrane encloses the contents of each sporocyst. Sporocysts fill the oocysts almost entirely. 
Characteristic features of the sporocyst - Boatshaped with a rounded end and in the opposite end, a pointed SB; it has large granular SR and two RBs; one of them is large and subspheroid, while the other one is smaller and round.

According to Duszynski and Wilber (1997), a new coccidian species should be compared in details with coccidian species that are the most feature-similar to it and that belong to the same host family. Therefore, the morphological characteristics of E. pavoaegyptica sporulated oocysts were compared to those of other Eimeria spp previously described in Galliformes and family Phasianidae. Only Eimeria patnaiki found parasitizing the same host species from India (Ray 1966), closely resembles the aforementioned, newly discovered species, which shows the presence of OR and the absence of M. However, we can differentiate these two species based on several significant morphological characteristics. With respect to E. pavoaegyptica, its oocysts are ellipsoidal in shape, significantly smaller in size $(15 \times$ 12) and enclose a single, large, rectangular PG, whereas those of E. patnaiki are spherical in shape, larger in size (17-19 × 13-17) and have a single, spherical PG. In addition, the shape of sporocysts also differentiates the newly discovered species because those of E. patnaiki are lemon-shaped, while the ones of E. pavoaegyptica are boat-shaped. Similarly, the presence of a small pointed SB with two different-sized RB in each SP and a uniformly granular SR covering the entire SP can easily differentiate the new parasite from E. pat$n a i k i$, which possess a vestigial SB with several small scattered SR granules within the sporocysts.

Eimeria indiana from Gallus gallus domesticus Linnaeus, 1758 (Bandyopadhyay et al. 2006) also closely resembles this new species in terms of the shape of the oocysts and in the absence of M, but it mainly differs from this newly described species in having a single ovoid PG and by the absence of OR. These aforementioned morphological distinctions and the different host genus make E. pavoaegyptica a distinctly separate form.

Moreover, E. pavoaegyptica can be distinguished from E. mayurai because it has much smaller oocysts, smaller sporocysts, presence of an OR and absence of an M. Similarly, it has a single large, rectangular PG rather than a small $\mathrm{M}$ and spherical PG. In addition, it can be differentiated by the character of the oocyst wall. The oocyst wall of E. pavoaegyptica appears bicolored, the outermost portion is red-brown and the innermost portion is yellowish-green, whereas the outer layer of the oocyst wall of E. mayurai is light blue.

The ovoidal-shaped oocyst form of E. pavonina and $E$. pavonis distinguishes these species from the ellipsoidalshaped oocyst form of E. pavoaegyptica. Furthermore, the absence of $\mathrm{M}$ also differentiates E. pavoaegyptica from E. pavonina and E. pavonis, which all have an M. Moreover, the measurements of E. pavoaegyptica oocysts and sporocysts do not overlap with the size ranges reported for both of the abovementioned species.

The primary differences between E. pavoaegyptica and Eimeria mandali revolve around the morphological features of the oocysts (ellipsoidal for E. pavoaegyptica vs. spherical for E. mandali), in the presence of an OR and in the shape of the PG.

E. pavoaegyptica can be easily distinguished from Eimeria arabica and Eimeria riyadhae because it has an OR and due to its smaller size $(15 \times 12)$. Furthermore, the oocyst wall characters differentiate the abovementioned two species from the new species. The outer layer of the oocyst wall of E. pavoaegyptica appears bicolored, the outermost portion is red-brown, the innermost portion yellowish-green and thick; whereas the outer layer of the oocyst wall of E. arabica and E. riyadhae is thin and yellowish and pale yellow, respectively. Furthermore, the new species is distinguished from E. arabica and E. riyadhae by the shape of the sporocysts. The sporocysts of the new species are boatshaped with two different-sized RBs in each SP, but those of E. arabica and E. riyadhae are elongate-ovoid with two same-sized RBs in each SP and ovoid with large globules at each end of the SP, respectively. Furthermore, Eimeria mutica is also distinct by the presence of M, bi-loped PG and the absence of OR, while Eimeria kharjensis is characterized by the presence of $M$ with a dome-shaped cap and a single spherical PG (Table). In spite of the different geographic origin, I included them in the differential diagnosis to avoid possible conspecificity potentially caused by the recent extensive international trade.

On the basis of the abovementioned differences, in addition to the geographic isolation of the hosts, I consider this newly discovered species, described here for the first time, to be a new coccidian and I propose to name it E. pavoaegyptica.

Type host - Indian peacock (P. cristatus).

Site of infection - Unknown, oocysts collected directly from host faeces.

Type locality - El-Gharbia Governorate, Egypt.

Type data and depository - El-Gharbia city zoo, Egypt. Phototypes of oocysts are deposited in the collection of the Museum of the Department of Parasitology in the Faculty of Veterinary Medicine, South Valley University, Egypt (Pavo 1).

Host-parasite data - Prevalence: four out of 15 (26.66\%).

Time of sporulation - Seventy two hours at RT $\left(23^{\circ} \mathrm{C}\right)$.

Etymology - The specific name was derived from the generic name of the host and the epithet "aegyptica" was given after the name of the country, Egypt, where the species was discovered.

\section{DISCUSSION}

Eimerian parasites of the genus Pavo are limited to the reports of E. pavonina (Banik \& Ray 1961); E. mandali (Banik \& Ray 1964); E. pavonis (Mandal 1965); E. mayurai (Bhatia \& Pande 1966); E. patnaiki (Ray 1966); E. riyadhae and E. arabica (Amoudi 1988) and all these species of Eimeria were recorded from Indian peacocks $P$. cristatus. In addition, E. mutica and E. 


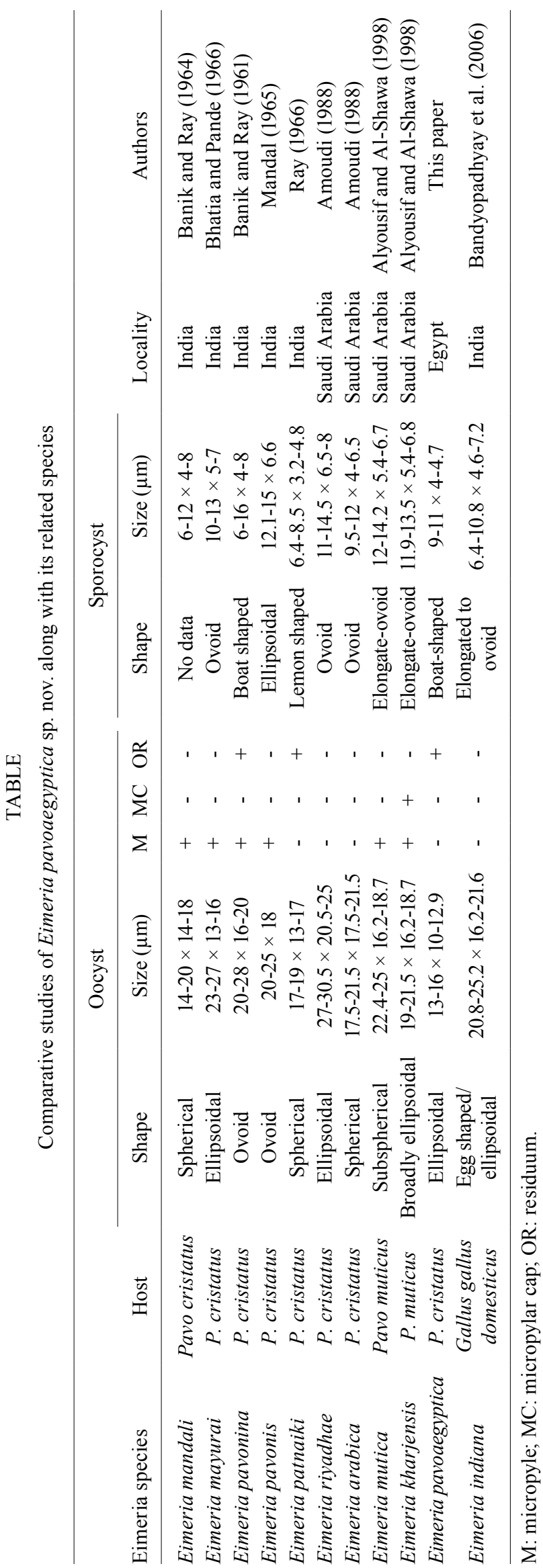

kharjensis have been reported from green peacock $P$. muticus in Saudi Arabia (Alyousif \& Al-Shawa 1998).

Interestingly, Eimerian parasites of birds are generally considered to be highly host specific not only under natural conditions (Hiepe \& Jungmann 1983) but also in farmed birds (Rommel 2000). Therefore, host systematic and geographic origin are commonly used criteria in their taxonomy.

The genus Eimeria represents the most specious genus within both protozoan and metazoan organisms. Until recently, more than 1,700 named Eimeria species have been described based on qualitative and quantitative traits of their sporulated oocyst and their host specificity (Duszynski \& Upton 2001).

Until recently, little data was available on eimeriid parasites of galliformes that infect game birds, such as peafowl, particularly regarding the African biodiversity. This dearth of information involves not only the classification of the species concerned but also the consequences of infection by the usually different types of pathogens on the health status of the hosts both at individual and population levels. Likewise, almost nothing is known on the seasonality and biology of coccidian infections in galliform captive birds. However, knowing how severe disease and high mortality can be caused in galliform birds in captivity (Rommel 2000). More detailed parasitological studies are needed and future research on game-bird population dynamics should not neglect protozoan infections, particularly the ones caused by coccidian parasites, which are of great importance for species conservation.

\section{ACKNOWLEDGEMENTS}

To the reviewers, for a careful review of the manuscript and to their positive comments that substantially improved this paper.

\section{REFERENCES}

Alyousif MS, Al-Shawa YR 1998. Two new coccidia (Apicomplexa: Eimeriidae) from the green peacock (Pavo muticus) from Saudi Arabia. Parasitol Int 47: 301-306.

Amoudi MA 1988. Two new species of Eimeria from peacocks (Pavo cristatus) in Saudi Arabia. J Protozool 35: 546-548.

Bandyopadhyay PK, Bhakta JN, Shukla R 2006. Eimeria indiana (Apicomplexa, Sporozoea), a new eimerian species from the hen, Gallus gallus domesticus (Aves, Phasianidae), in India. Protistology 4: 203-206.

Banik DC, Ray HN 1961. On a new coccidium, Eimeria pavonina $\mathrm{n}$. sp. from peacock, Pavo cristatus linn. Bull Calcutta Sch Trop Med 9: 61.

Banik DC, Ray HN 1964. On a new coccidium Eimeria mandali n. sp. from the Indian peacock. Bull Calcutta Sch Trop Med 12: 27.

Bhatia BB, Pande BP 1966. A new coccidium, Eimeria mayurai (Sporozoa: Eimeriidae) from the common peafowl Pavo cristatus L. Proc Natl Acad Sci India 36: 39-42.

Brown HW, Neva FA 1983. Basic clinical parasitology, 5th ed., Appleton-Century-Crofts, Connecticut, p. 319-321.

Daszak P, Cunningham AA, Hyatt AD 2000. Emerging infectious diseases of wildlife-threats to biodiversity and human health. Science 287: 443-449. 
Duszynski DW, Upton SJ 2001. The common coccidia of wild mammals: Cyclospora, Eimeria (Eimeriidae) and Cryptosporidium (Cryptosporidiidae) spp. In WM Samuel, MJ Pybus, AA Kocan (eds.), Parasitic diseases of wild mammals, Iowa State University Press, Ames, p. 416-433.

Duszynski DW, Wilber PG 1997. A guideline for the preparation of species descriptions in the Eimeriidae. J Parasitol 83: 333-336.

Freitas MFL, Oliveira JB, Cavalcanti MDB, Leite AS, Magalhaes VS, Oliveira RA, Evencio-Sobrino A 2002. Gastrointestinal parasites of captive wild birds in Pernambuco state, Brazil. Parasitol Latinoam 57: 50-54.

Hiepe T, Jungmann R 1983. Lehrbuch der parasitologie, Bd2, Veterinärmedizinische Protozoologie, Fischer Verlag, Jena, 101-110.

Levine ND 1985. Veterinary protozoology, Iowa State University Press, Ames, 414 pp.

Mandal AK 1965. Studies on some aspects of avian coccidia (Protozoa: Sporozoa). 3. Five new species of the genus Eimeria Schnedier, and a new subspecies of Eimeria roscoviensis (Labbe). Proc Zool Soc (Calcutta) 18: 47-57.

Pellerdy LP 1965. Coccidia and coccidiosis, Akademiai Kiado Publishing House of the Hungarian Academy of Science, Budapest, $657 \mathrm{pp}$.

Ray HN 1966. Remarks on Eimeria pavonis n. sp. from Indian peacock (Pavo cristatus). Indian J Microbiol 6: 51-52.

Rommel M 2000. Parasitosen des nutzgeflügels (Huhn, Truthuhn, Gans, Ente, Taube). In M Rommel, J Eckert, E Kutzer, W Körting, T Schnieder (eds.), Veterinärmedizinische parasitologie, Parey Buchverlag, Berlin, p. 673-774.

Soulsby EJL 1982. Helminths, arthropods and protozoa of domesticated animals, Academic press, London, p. 630-639.

Wilber PG, Duszynski DW, Upton SJ, Seville RS, Corliss JO 1998. A revision of the taxonomy and nomenclature of the Eimeria spp (Apicomplexa: Eimeriidae) from rodents in the Tribe Marmotini (Sciuridae). Syst Parasitol 39: 113-135. 